\title{
Local Earthquake Magnitude Scale and Seismicity Rate for the Ethiopian Rift
}

\author{
by Derek Keir, G. W. Stuart, A. Jackson,* and A. Ayele
}

\begin{abstract}
A calibrated local earthquake magnitude scale is essential for quantitative analyses of seismicity. In Ethiopia, effective monitoring of earthquakes and resulting assessment of seismic hazard are especially important as regions with seismic and volcanic activity coincide with regions of economic significance and population growth. We have developed a local magnitude $\left(M_{\mathrm{L}}\right)$ scale for the northern Main Ethiopian rift (MER) using earthquake data collected during 2001-2003 on 122 three-component broadband seismic stations. Waveform data from 2139 local earthquakes were corrected for instrument response and convolved with the nominal Wood-Anderson torsion seismograph response appropriate for the original definition of local magnitude. The hypocentral distances considered are 5 to $800 \mathrm{~km}$, with the best represented range from 5 to $150 \mathrm{~km}$. A total of 30,908 maximum zero-to-peak amplitudes $\left(A_{W A}\right)$ were incorporated into a direct linear inversion for individual earthquake local magnitudes $\left(M_{\mathrm{L}}\right), 244$ station factors $(C)$, and 2 linear distance-dependent factors $(n, K)$ in the distance correction term, $\log \left(A_{\mathrm{o}}\right)$, of the equation for local magnitude: $M_{\mathrm{L}}=\log \left(A_{W A}\right)-\log \left(A_{\mathrm{o}}\right)+C$. The resulting distance correction is given by $-\log \left(A_{\mathrm{o}}\right)=1.196997 \log (r / 17)+0.001066(r-17)+2$, which implies that ground-motion attenuation is relatively high, consistent with ongoing magma intrusion and the presence of shallow magma reservoirs beneath the MER. Station corrections significantly reduce $M_{\mathrm{L}}$ residuals and range between $\pm 0.42 M_{\mathrm{L}}$ units. The catalog of earthquakes is complete above $M_{\mathrm{L}} \sim 2.1$ and the annual cumulative seismicity rate follows the relation $\log N=4.5-1.13 M_{\mathrm{L}}$. Our results are critical for accurate routine quantitative analysis of past, current and, future seismicity in Ethiopia.
\end{abstract}

\section{Introduction}

The northern Main Ethiopian rift (MER) and Afar rifts are virtually the only places worldwide where the transition between continental and oceanic rifting is subaerially exposed. As part of project EAGLE (Ethiopia Afar Geoscientific Lithospheric Experiment), up to 179 broadband seismic stations were deployed across a $250 \times 350 \mathrm{~km}$ area of the Ethiopian rift and adjacent uplifted plateaus (e.g., Bastow et al., 2005 Maguire et al., 2006) (Fig. 1). The data were collected from the EAGLE network and seismicity was analyzed to study the pattern of strain localization just prior to continental breakup (Keir et al., 2006). We aim to quantify the size of local earthquakes in our dataset by accurately estimating local earthquake magnitude $\left(M_{\mathrm{L}}\right)$. The wealth of broadband waveforms in the seismicity dataset allows us to undertake a direct inversion of earthquake-amplitude mea-

*Present address: Institut fur Geophysik, ETHZ Honggerberg, CH-8093 Zurich, Switzerland: andrew.jackson@erdw.ethz.ch. surements for a local magnitude scale based on the original definition proposed by Richter $(1935,1958)$. The calibrated magnitude scale is then used to calculate the annual cumulative frequency-magnitude distribution of seismicity in the MER.

A calibrated earthquake-magnitude scale based on $M_{\mathrm{L}}$ is of great importance for seismic-hazard studies (Bormann, 2002). Attenuation curves that correct for the decrease in seismic-wave amplitude with distance differ from region to region and the use of an inappropriate curve can result in miscalculation of earthquake magnitude by over $1 M_{\mathrm{L}}$ units, even at hypocentral distances of less than $300 \mathrm{~km}$ (Fig. 2). Probabilistic hazard analysis requires details of magnitude statistics (e.g., maximum magnitudes and the $b$-value of the cumulative frequency-magnitude distribution), which require accurate magnitude estimates to determine earthquakerecurrence relationships. The combination of the sparse station distribution, lack of a calibrated local-magnitude scale, and low number of earthquakes recorded on global, regional, 

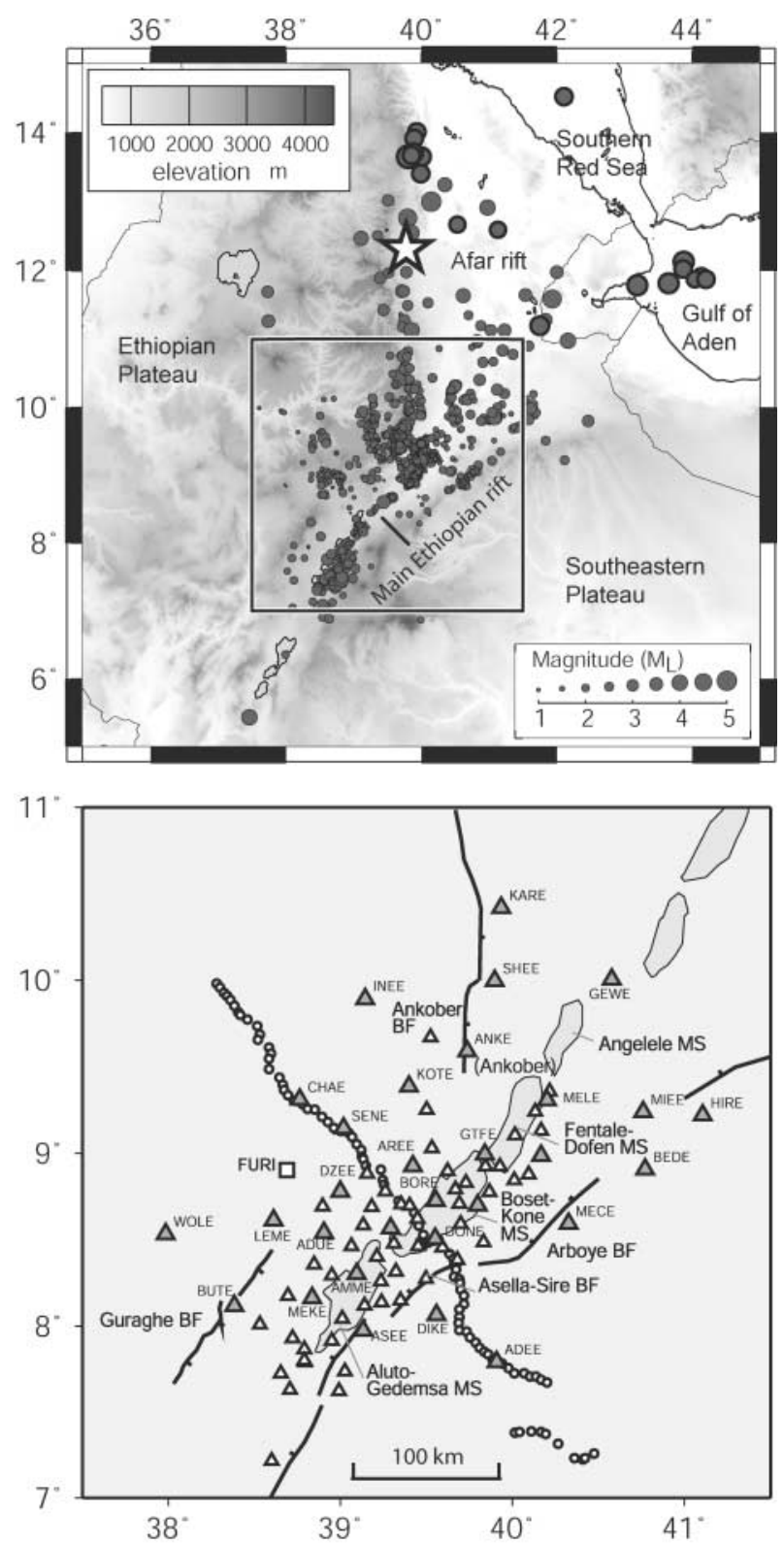

Figure 1. (Top) Distribution of the 2139 earthquakes recorded from October 2001 to January 2003 in the MER and Afar rifts. Size of earthquake epicenters is scaled by magnitude. The white star is the location of NEIC-reported earthquake 1 December 2002 11:18 $\left(m_{\mathrm{b}}\right.$ Preliminary Determination of Epicenter $[\mathrm{PDE}]=4.9)$. The box encloses the location of the EAGLE network of broadband seismic stations. (Bottom) Location of EAGLE network broadband seismic stations. Dark triangles with station names are CMG3T and CMG-40TD stations that operated from October 2001 to January 2003. Light triangles are CMG6TD stations that operated from October 2002 to January 2003. Circles are CMG-6TD stations that operated from November 2002 to January 2003. IRIS/ GSN permanent broadband station FURI is shown as a white square. Rift bounding Miocene border faults (BF) are shown with thick black lines and dip ticks. Right-stepping, en echelon magmatic segments (MS) along the rift axis are shaded grey.

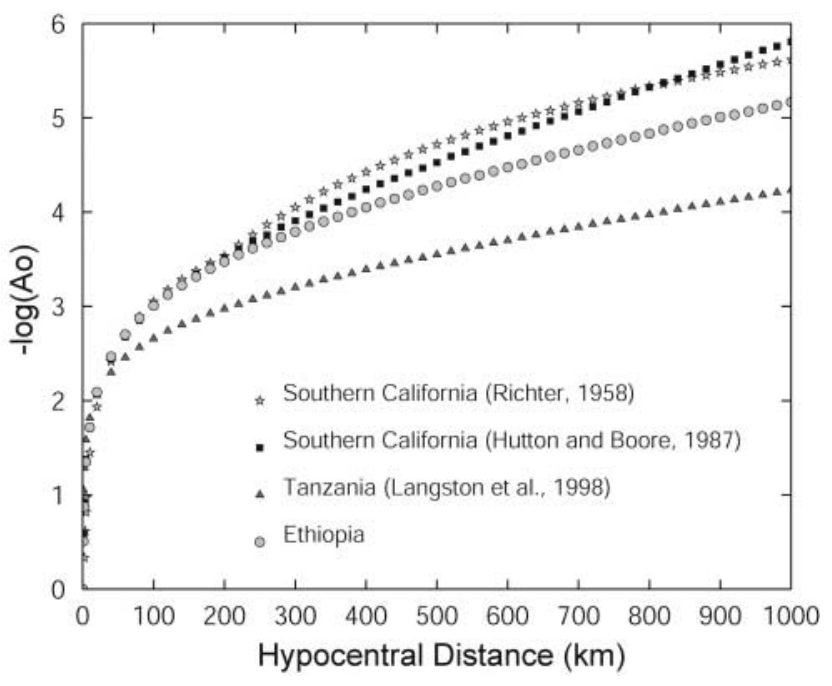

Figure 2. Attenuation curves for southern California (Richter, 1935, Hutton and Boore, 1987), for Tanzania (Langston et al., 1998), and for Ethiopia (from our study).

and local catalogs has meant that reliable earthquakemagnitude statistics for the MER have not been calculated (Ayele and Kulhánek, 1997). Earthquake magnitude is also important in integrated seismic and geodetic studies that aim to understand lithospheric deformation processes in rift systems by quantifying relative amounts of seismic and aseismic strain (e.g., Hofstetter and Beyth, 2003; Bendick et al., 2006). The attenuation curve derived from a local magnitude scale is also useful for risk assessment in engineering practice as the frequency band of the Wood-Anderson seismometer $(\sim 0.8-10 \mathrm{~Hz})$ is in the range of most engineering structures. However, measurements on seismic-wave propagation in Ethiopia are lacking (Kebede and van Eck, 1997; Mammo, 2005).

Seismic-hazard assessment is important in Ethiopia because regions with seismic activity coincide with regions of economic significance and population growth (e.g., Gouin, 1979; Kebede and Kulhánek, 1991, 1994). The potential seismic and volcanic hazard in volcanic rift zones in Ethiopia was highlighted by the recent rifting episode in the northern Afar rift. From 14 September to 4 October 2005, 163 earthquakes of $m_{\mathrm{b}}>4.0$ and a volcanic eruption occurred within a $\sim 60-\mathrm{km}$-long rift segment. Disruption caused by ground shaking, surface fissuring, and ash deposits caused the displacement of $\sim 6000$ pastoralists from the region (Yirgu et al., 2005). Radar interferometry (InSAR) shows that up to $\sim 8 \mathrm{~m}$ of horizontal opening occurred during the rifting event with seismic-moment release accounting for less than $7 \%$ of observed deformation (Wright et al., 2006). Most extension was likely accommodated by dike intrusion.

Seismicity in Ethiopia is currently monitored by five permanent broadband seismic stations, including the Incorporated Research Institutions for Seismology/Global Seis- 
mographic Network (IRIS/GSN) station FURI, maintained by the Geophysical Observatory Addis Ababa University. The Geophysical Observatory records earthquake coda length and uses the relationship $M_{\mathrm{d}}=1.97 \log \tau+0.0008 \Delta-$ 1.28 , where $\tau$ is coda length in seconds, and $\Delta$ is hypocentral distance in kilometers to determine duration magnitude $\left(M_{\mathrm{d}}\right)$ (Asfaw, 1988). No relationship between displacement amplitude and local magnitude $\left(M_{\mathrm{L}}\right)$ has yet been determined, however. In addition to the permanent stations, seismicity of north Afar has been monitored by a network of eight threecomponent broadband seismic stations since October 2005. A calibrated magnitude scale is critical for accurate quantitative monitoring of past, ongoing, and future seismic activity in Ethiopia.

\section{Tectonic Setting}

The Miocene-Recent MER constitutes the northern part of the East African rift system and forms the youngest arm of the Afar triple junction, which developed in an EoceneOligocene flood basalt province (Fig. 1). The MER is bounded by northeast-trending Miocene border faults. Since Quaternary times extensional strain has localized in $<20$ $\mathrm{km}$-wide right-stepping en echelon magmatic segments, which are zones of north-northeast-striking fissures, faults, and aligned volcanic cones (Bilham et al., 1999; Ebinger and Casey, 2001).

Most of the seismicity from October 2001 to January 2003 occurred at the oblique intersection between the southern Red Sea rift and MER near Ankober, and within the Fentale-Dofen magmatic segment (Keir et al., 2006) (Fig. 1). Earthquakes were predominantly $8-14 \mathrm{~km}$ deep (Keir et al., 2006). Records of seismicity over the past $\sim 150$ years show a similar pattern with seismicity concentrated near Ankober and within the en echelon magmatic segments along the axis of the MER (e.g., Gouin, 1979; Asfaw, 1982; Kebede and Kulhánek, 1994; Ayele and Kulhánek, 1997; Hofstetter and Beyth, 2003). The spatial correlation between seismicity and aligned cones in magmatic segments suggests that earthquakes are induced by dike injection, and the temporal patterns of seismicity suggest that magmatic segments are fed from discrete sources of magma and that extension occurs mainly in episodic dike-injection events (Keir et al., 2006).

Geodetic, structural, and seismic studies show that the majority of strain across the MER is accommodated by dike injection beneath magmatic segments. A comparison of seismic-moment release and total opening strain predicted from plate separation rates shows that $>50 \%$ of strain is accommodated aseismically (Hofstetter and Beyth, 2003). Keranen et al. (2004) interpret high-velocity anomalies in controlled source tomographic images as $\sim 20-\mathrm{km}$-wide axial mafic intrusions at $\sim 10 \mathrm{~km}$ depth beneath magmatic segments. $S$-wave splitting in local earthquakes shows the fastpolarization direction in magmatic segments parallel to aligned volcanic cones with the amount of splitting highest in regions of probable partial melt. From these observations Keir et al. (2005) proposed that anisotropy of the upper $\sim 10 \mathrm{~km}$ beneath the rift is caused by aligned melt and dikes. Magma intrusions are likely not restricted to crust beneath rift valley magmatic segments as midcrustal conductive anomalies in magnetotelluric (MT) data indicate the presence of partial melt in the lower midcrust beneath the Ethiopian plateau (Whaler and Hautot, 2006).

Seismic studies that probe mantle structure provide constraints on the distribution of partial melt at depth. Anomalous low-velocity zones in the upper asthenosphere are segmented beneath the rift valley and also impinge beneath the Ethiopian plateau. Comparison of relative $P$ - and $S$-arrival times shows that they are likely due to a combination of high temperatures and partial melt (Bastow et al., 2005). Both the large amount of SKS splitting and the rift parallel orientation of the fast polarization direction led Kendall et al. (2005) to propose that partial melt beneath the MER rises through dikes that penetrate the thinned lithosphere. In addition, $S v$ and $S h$ velocity models derived from surface-wave dispersion curves are consistent with a model of anisotropy due to aligned melt-filled pockets from $20-75 \mathrm{~km}$ depth beneath the rift (Kendall et al., 2006).

\section{Amplitude Data}

Local earthquakes were recorded on 29 broadband seismic stations (EAGLE Phase I) that were operational between late October 2001 and January 2003 (Fig. 1). These threecomponent Güralp CMG-3T and CMG-40TD instruments recorded continuous data at $50 \mathrm{~Hz}$. Additional data during this period were acquired from the permanent IRIS/GSN broadband station FURI. The number of seismic stations was increased during the final 4 months of the experiment with the deployment of an additional 50 CMG-6TD broadband instruments recording at $100 \mathrm{~Hz}$. These stations were deployed at $\sim 15-\mathrm{km}$ spacing mainly in the rift valley, and they were operational between October 2002 and February 2003 (EAGLE Phase II). A further 100 broadband CMG-6TD instruments deployed at $\sim 5-\mathrm{km}$ spacing across the rift valley and adjacent plateaus were operational between November 2002 and January 2003 (EAGLE Phase III).

During the 16 months of the EAGLE passive experiment, 2139 earthquakes recorded at four or more stations were located with the Hypo2000 algorithm (Klein et al., 2002) (Fig. 1). The earthquakes were located using a 1D velocity model determined by simultaneously relocating earthquakes and inverting for velocity structure (Daly et al., unpublished manuscript, 2006); 1957 earthquakes were located within the EAGLE network. We estimate hypocenter accuracy of $\pm 600 \mathrm{~m}$ in horizontal directions and $\pm 1500 \mathrm{~m}$ in depth for earthquakes recorded at eight or more stations (Keir et al., 2006). Earthquakes within the network recorded by between four and eight stations have estimated hypocental uncertainties of $<5 \mathrm{~km}$ in both horizontal directions and depth. Earthquakes located outside the network have estimated hypocen- 
tral uncertainties of up to $\sim 20 \mathrm{~km}$ in horizontal directions and $\sim 10 \mathrm{~km}$ depth.

Local magnitude was originally defined by Richter (1935) using ground motions recorded on a standard horizontal Wood-Anderson torsion seismograph. Therefore, the EAGLE broadband data were corrected for the instrument response of the CMG-3T, CMG-40TD, and CMG-6TD seismometers. The displacement ground motions were convolved with the standard Wood-Anderson response: magnification of 2800, damping ratio of 0.8 , and natural period of $0.8 \mathrm{sec}$ (Anderson and Wood, 1925; Kanamori and Jennings, 1978). We measured the maximum absolute value of the zero-to-peak amplitude in millimeters of the north-south and east-west horizontal component seismograms. Stations with malfunctioning horizontal components were removed from the dataset. The dataset includes 15,456 amplitude measurements on each horizontal component, a total of 30,908 measurements (Fig. 3). The hypocentral distances considered range from 5 to $800 \mathrm{~km}$, with the best represented range being from 5 to $150 \mathrm{~km}$ (Fig. 3).

\section{Methodology}

We use the equation of Richter $(1935,1958)$

$$
M_{\mathrm{L}}=\log \left(A_{W A}\right)-\log \left(A_{\mathrm{o}}\right)+C,
$$

where $A_{W A}$ is zero-to-peak amplitude measured on a standard horizontal Wood-Anderson seismograph, $\log \left(A_{\mathrm{o}}\right)$ is a distance correction term, and $C$ is a correction term for individual stations. We determine the attenuation curve, $\log \left(A_{\mathrm{o}}\right)$, by using the parametric approach (Bakun and Joyner, 1984). The major advantages of the parametric form of the attenuation curve are that it considers simple expressions of geometrical spreading and attenuation, and is represented by only a few coefficients. This facilitates straightforward estimation of local magnitude using a single equation at all hypocentral distances (e.g., Hutton and Boore, 1987; Kim, 1998; Langston et al., 1998; Kim and Park; 2005). On a global scale, the standardization of the local magnitude calculation using the parametric form of the attenuation curve is recommended (Ortega and Quintanar, 2005). A drawback of the parametric approach is that the nonparametric expression of the attenuation curve better represents crustal and upper-mantle complexities (e.g., Anderson and Lei, 1994; Savage and Anderson, 1995; Baumbach et al., 2003; Bragato and Tento, 2005).

Richter's original local magnitude scale is defined such that an earthquake of $M_{\mathrm{L}} 3$ will cause a 1-mm zero-to-peak deflection of the Wood-Anderson seismogram at $100 \mathrm{~km}$ from the hypocenter. Hutton and Boore (1987) observed that if the attenuation within the first $100 \mathrm{~km}$ has a large geographic variation, earthquakes in different regions with the same $M_{\mathrm{L}}$ may have very different ground motions near the source, thus making $M_{\mathrm{L}}$ a poor measure of source size. To avoid this difficulty, they suggest that local magnitudes be

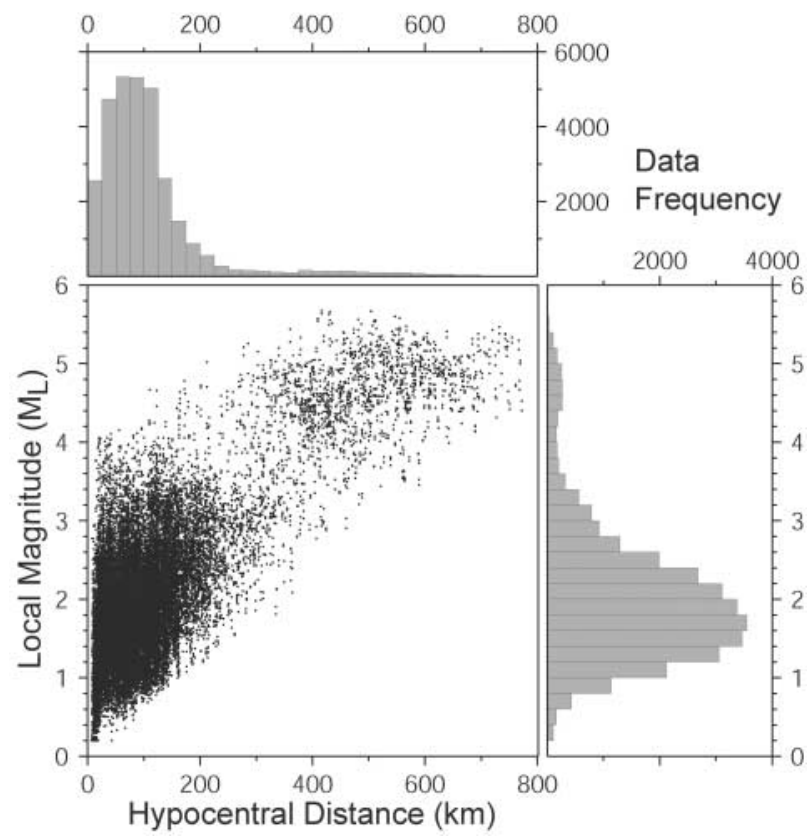

Figure 3. Distance/magnitude distribution of the data available for the horizontal components. Magnitudes are estimated with the new distance-correction terms for Ethiopia.

normalized to motions at closer distances to avoid most of the regional differences in wave propagation, using a 10$\mathrm{mm}$ deflection of the Wood-Anderson seismogram at $17 \mathrm{~km}$ from the hypocenter for a $M_{\mathrm{L}} 3$ earthquake, consistent with the original definition of the local magnitude scale. The shift to normalization nearer the source should only be used if the distribution of data is such that the attenuation curve can be evaluated with sufficient precision down to the new reference distance (Alsaker et al., 1991). This is the case with our dataset, which includes 2564 amplitude measurements (8\% of the dataset) at hypocentral distances of less than $25 \mathrm{~km}$ (Fig. 3). The distance correction term is thus defined as

$$
-\log \left(A_{\mathrm{o}}\right)=n \log (r / 17)+K(r-17)+2,
$$

where $r$ is hypocentral distance in kilometers, and $n$ and $K$ are parameters related to the geometrical spreading and attenuation of $S$ waves in the region, respectively.

If equations (1) and (2) are combined, the observed amplitude, $A_{i j k}$, is modeled by

$$
\begin{aligned}
\log \left(A_{i j k}\right)+2=-n & \log \left(r_{i j} / 17\right) \\
& -K\left(r_{i j}-17\right)+M_{\mathrm{L} i}-C_{j k},
\end{aligned}
$$

where index $i$ labels events, index $j$ labels stations, and index $k$ labels the component (north-south or east-west). The objective of the inversion is to determine $n, K, M_{\mathrm{L}}$, and $C$. There are two station factors per station corresponding to the east-west and north-south horizontal components. The system of equations includes a constraint that the mean of sta- 
tion factors is zero. The observations on the left-hand side of equation (3) are linearly related to the unknowns, which we arrange in a model vector $\mathbf{m}$. We have $N_{e}$ events and $N_{s}$ stations, and thus have a total of $\left(N_{e}+2 N_{s}\right)+2$ unknowns. The $N$ observations $\log \left(A_{i j k}\right)+2$ are arranged into the $N$ vector d. We write the overdetermined set of equations (3) in the form

$$
\mathbf{d}=\mathbf{A m},
$$

which we solve using the conventional least-squares criterion; the optimal solution satisfies

$$
\mathbf{m}=\left(\mathbf{A}^{T} \mathbf{A}\right)^{-1} \mathbf{A}^{T} \mathbf{d}
$$

The linear system (5) has a total of 2385 parameters and 30,908 data; it can be solved in less than an hour on a modest workstation. Our approach leads directly to an optimal solution and is different from the iterative procedure used to determine m (e.g., Langston et al., 1998). Pujol (2003) tested the direct inversion method on data from Tanzania previously analyzed with the iterative technique (Langston et al., 1998). Similar results were achieved but the major advantages of the direct inversion are that the solution is independent of the starting values for the unknowns.

\section{Results}

\section{Magnitude Scale for the MER}

The distance correction, $\log \left(A_{\mathrm{o}}\right)$, term from the inversion using $17-\mathrm{km}$ distance normalization is given by:

$$
\begin{aligned}
-\log \left(A_{\mathrm{o}}\right)=1.196997 & \log (r / 17) \\
& +0.001066(r-17)+2
\end{aligned}
$$

where $r$ is hypocentral distance in kilometers (Fig. 2).

The errors on the estimates of $n$ and $K$ can be determined from the posterior covariance matrix. The two-by-two subsection of the entire 2385 by 2385 covariance matrix is practically diagonal, showing that the estimates of $n$ and $K$ are virtually independent. One can rigorously characterize this by calculating the eigenvectors of the $(n, K)$ section of the matrix; the ellipse describing the one standard deviation contour has a semimajor axis of length 0.025 and semiminor axis of length $9.7 \times 10^{-5}$ and is oriented with the semimajor axis practically parallel to the $n$ axis (the angle between them is $0.25^{\circ}$ ). These values for the ellipse lengths are similar to the values for the one-sigma standard deviations of the parameters $n$ and $K$.

The new distance-correction terms compensate correctly for the reduction in amplitude with increasing distance (Figs. 4 and 5). For example, earthquake 1 December 2002 11:18 $\left(m_{\mathrm{b}}\right.$ PDE $\left.=4.9\right)$ was the nearest and most widely recorded earthquake on the EAGLE network that was reported by National Earthquake Information Center (NEIC).
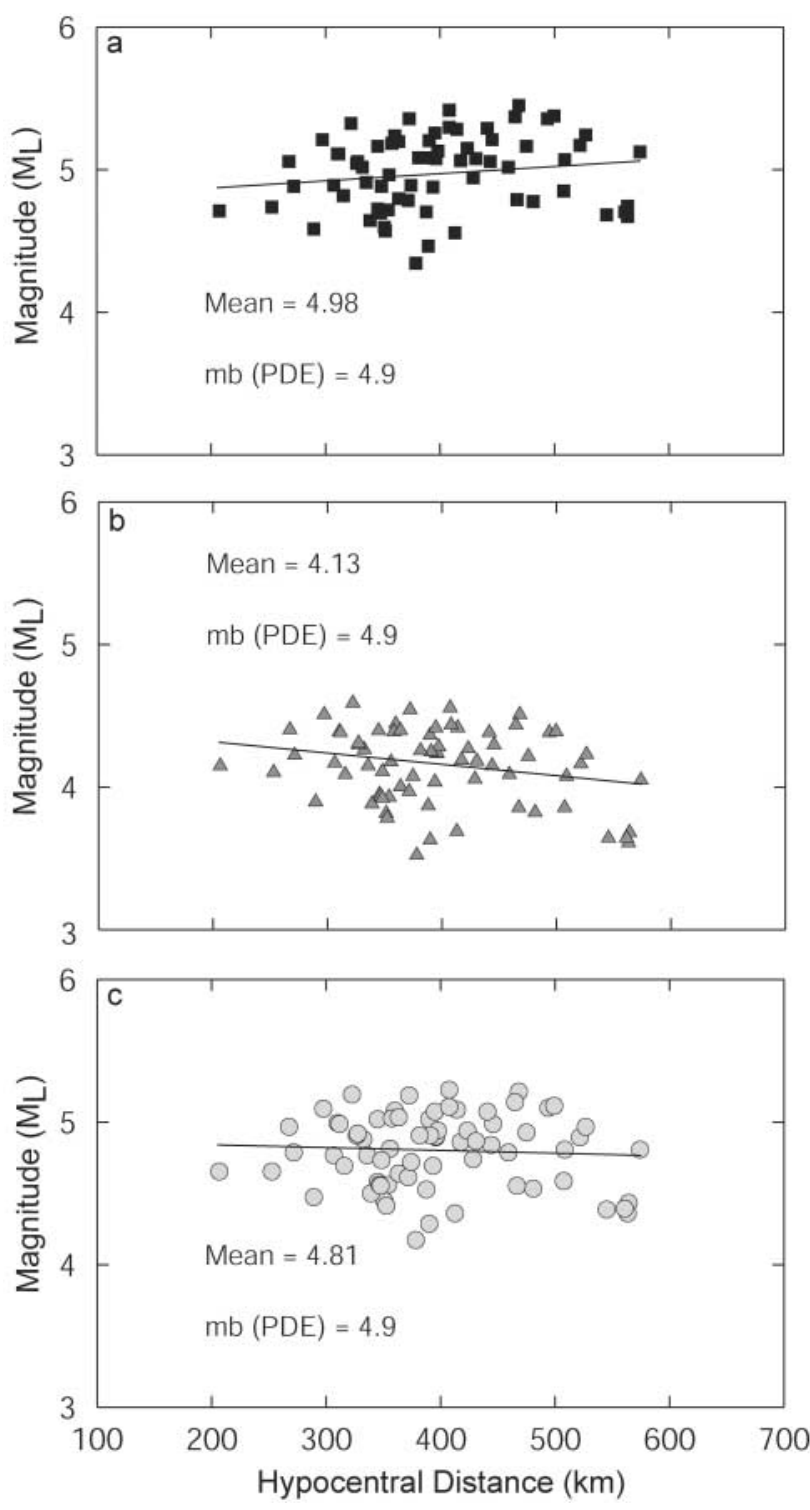

Figure 4. Magnitude estimated at stations of varying hypocentral distances for earthquake 1 December 2002 11:18 $\left(m_{\mathrm{b}}\right.$ PDE $\left.=4.9\right)$ with three different attenuation curves (a) magnitude estimated with the distance-correction terms of Hutton and Boore (1987) for southern California; (b) magnitude estimated with the distance correction terms of Langston et al. (1998); (c) magnitude estimated with the new magnitude scale for Ethiopia. Straight lines are best-fit to the data and show that the Hutton and Boore (1987) magnitude scale overestimates magnitudes with increasing hypocentral distances, whereas the Langston et al. (1998) scale underestimates magnitude with increasing hypocentral distance. The new magnitude scale for the MER estimates consistent magnitudes across varying hypocentral distances and the average local magnitude $\left(M_{\mathrm{L}} 4.81\right)$ is that expected for an $m_{\mathrm{b}} 4.9$ earthquake. 
The earthquake is located $\sim 200 \mathrm{~km}$ north of station KARE and was recorded with a high signal-to-noise ratio by 72 EAGLE broadband stations at hypocentral distances of 200$600 \mathrm{~km}$ (Fig. 4). Local magnitude was estimated at each station using the magnitude scale for Tanzania (Langston et al., 1998), southern California (Hutton and Boore, 1987), and Ethiopia. The magnitude estimated at each station using the Tanzania magnitude scale decreases with increasing hypocentral distance and the average magnitude is $M_{\mathrm{L}} 4.13$. In contrast, the magnitude at each station using the southern California scale increases with increasing hypocentral distance and the average magnitude is $M_{\mathrm{L}} 4.98$. The new magnitude scale for Ethiopia estimates consistent magnitude for stations at different hypocentral distances and the average magnitude is $M_{\mathrm{L}} 4.81$.

Also, magnitude residuals for the whole dataset were computed as the difference between magnitude assigned by a single station for a given earthquake and the average magnitude of the same earthquake. The mean magnitude residual is calculated per $50-\mathrm{km}$ bin interval with error bars marked by the standard deviation of the mean magnitude residuals (Fig. 5). Mean magnitude residuals vary $\pm 0.1 M_{\mathrm{L}}$ units to hypocentral distance of $700 \mathrm{~km}$. An $M_{\mathrm{L}}$ residual of 0.18 is calculated from only 16 measurements at hypocentral distances of $>700 \mathrm{~km}$. The lack of significant variation in mean magnitude residuals with distance shows that possible complexities in crustal and upper-mantle structure do not have a systematic effect on variations in attenuation with distance beneath the MER. Our parametric expression of the attenuation curve thus represents a simple model that adequately compensates for the decay of amplitude with increasing distance.

\section{Local Magnitude Values and Station Corrections}

The inversion procedure solved for correction factors of both north-south and east-west components at individual stations. Magnitude residuals were calculated with and without computed station corrections, $C$, taken into account (Fig. 6). For magnitude residuals calculated without station correction, the average of residuals on the north-south and east-west components is nearly zero and the standard deviation is 0.24 (variance, $\sigma^{2}$, is 0.058 ). For magnitude residuals calculated with station corrections, the average of residuals on the north-south and east-west components is nearly zero, and the standard deviation is 0.18 ( $\sigma^{2}$ is 0.032$)$. Therefore, adopting the station corrections reduced variance by $45 \%$.

The north-south component correction factors vary between 0.41 and $-0.34 M_{\mathrm{L}}$ units and the east-west component correction factors vary between 0.42 and $-0.33 M_{\mathrm{L}}$ units (Fig. 7). Most stations have similar correction factors on the two horizontal components. Station corrections can vary dramatically over distances of $\sim 5 \mathrm{~km}$ and there is no consistent difference between corrections at stations in the rift valley and on the adjacent plateau. Thus, the spatial vari-

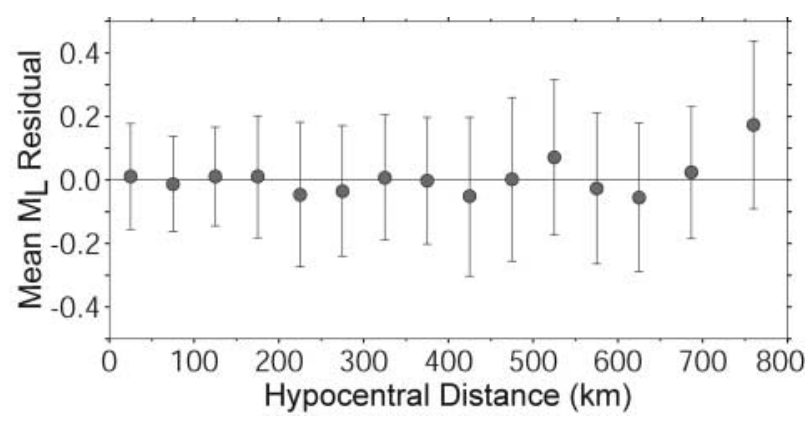

Figure 5. Mean magnitude residuals calculated per 50-km bin intervals with error bars marked by the standard deviation in the mean magnitude residuals. Magnitude residuals were computed as the difference between magnitude assigned by a single station and the average magnitude of the earthquake. The lack of significant variation in mean magnitude residuals with distance shows that possible complexities in crustal and upper-mantle structure do not have a systematic effect on variations in attenuation with distance.

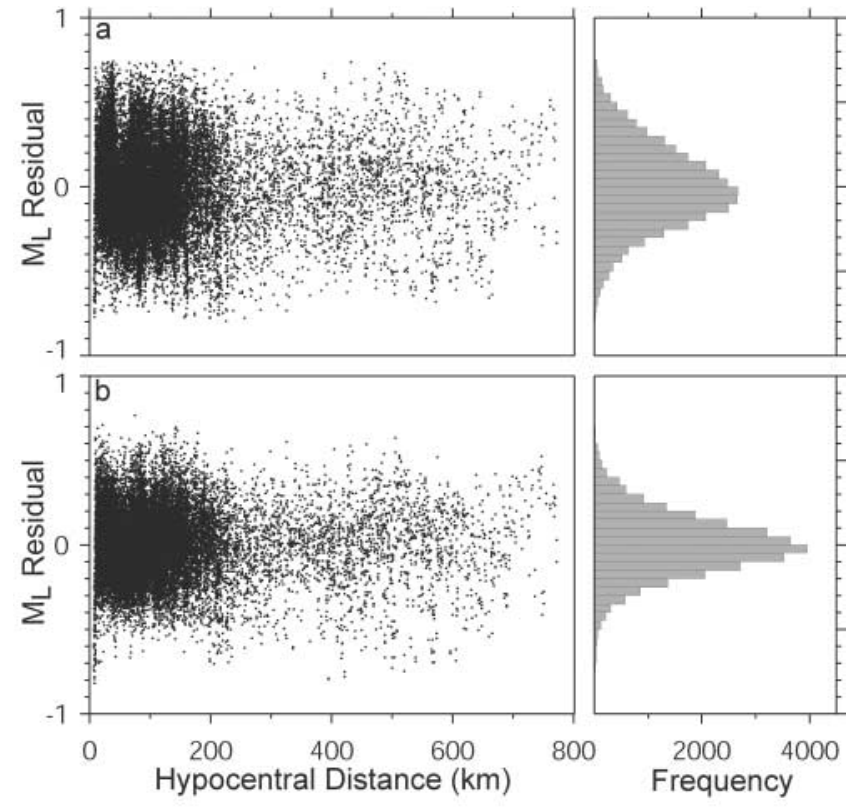

Figure 6. Magnitude residuals/hypocentral distance distributions for both the north-south and eastwest components. (a) Magnitude residuals without taking into account station corrections. The standard deviation is 0.24 and variance $\sigma^{2}$ is 0.058 . (b) Magnitude residuals with station corrections taken into account. The standard deviation is 0.18 and variance $\sigma^{2}$ is 0.032 . Therefore, adopting the station corrections reduced variance by $45 \%$. The average of residuals, both with and without station corrections considered, is nearly zero. 


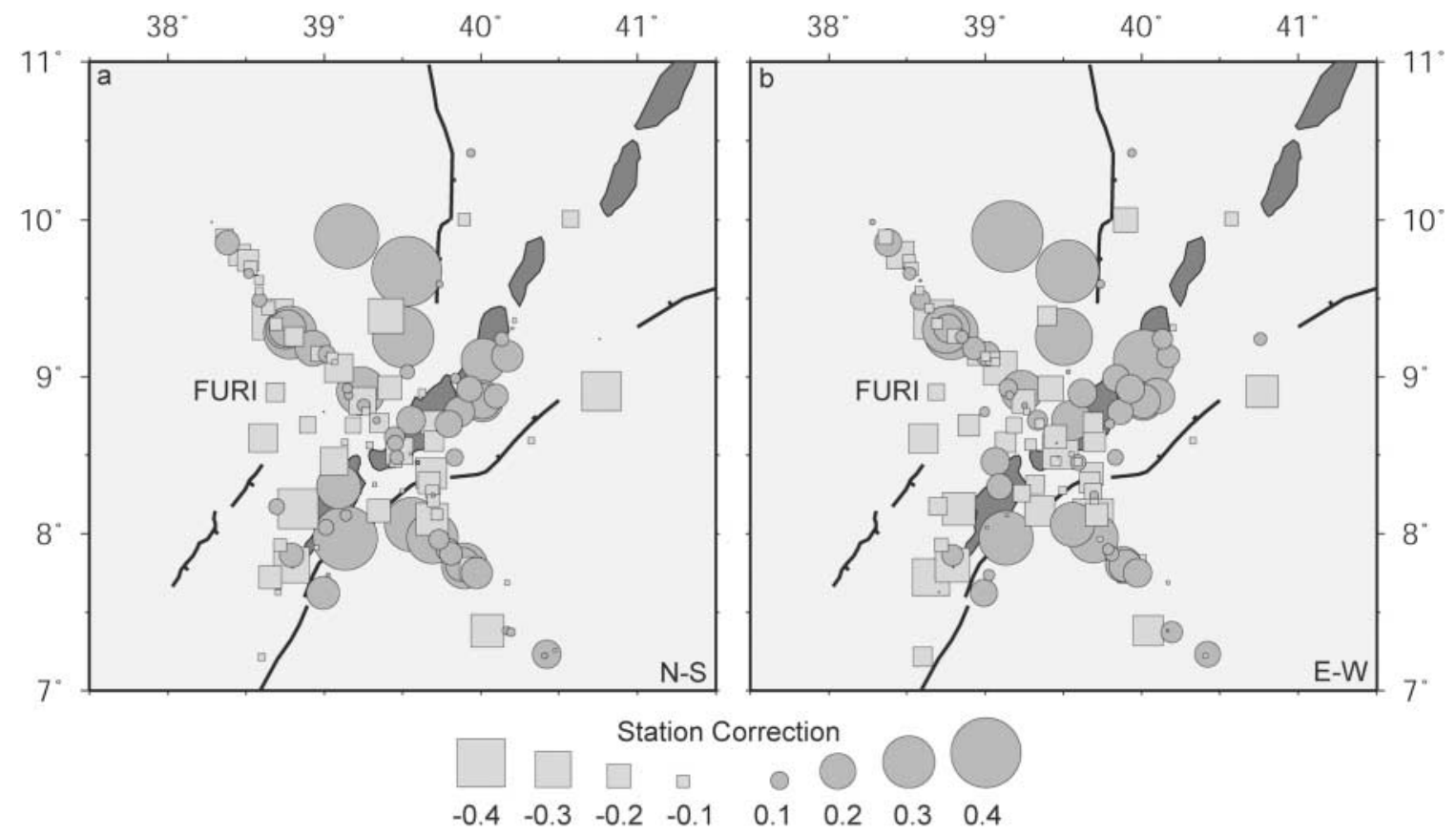

Figure 7. Spatial variation of station factors on north-south component (a) and eastwest component (b). Negative correction factors are shown as squares scaled by magnitude of the correction factor. Positive correction factors are shown as circles scaled by magnitude of the correction factor.

ation of station factors shows neither a clear correlation to major tectonic features nor to topographic relief and suggests a strong influence of local site effects on variations in the amplitude of ground motion.

The station correction factors for the permanent IRIS/ GSN station FURI are $-0.16 M_{\mathrm{L}}$ units on the north-south component and $-0.14 M_{\mathrm{L}}$ units on the east-west component. Future permanent and temporary seismic-array deployments in Ethiopia are likely to include earthquake records from FURI, and such studies will now be able to use amplitude measurements from this permanent station to calibrate new data with our magnitude scale for the MER.

\section{Discussion}

A comparison of the attenuation curves obtained from Ethiopia, southern California (Hutton and Boore, 1987), and Tanzania shows that attenuation in Ethiopia is relatively high. The attenuation curve computed for southern California by Hutton and Boore (1987) is similar to Ethiopia, in particular, at hypocentral distances of less than $300 \mathrm{~km}$. Rifted regions with elevated geothermal gradients such as the southwestern United States are in general characterized by high attenuation of seismic waves (e.g., Richter, 1958; Hutton and Boore, 1987; Savage and Anderson, 1995). In southern California, high body-wave attenuation in the lower crust beneath the Salton Trough and San Gabriel Mountains is attributed to a combination of high temperatures and partial melt (Schlotterbeck and Abers, 2001). Our results of relatively large amounts of attenuation in the MER are thus not surprising considering the wealth of independent geophysical and geological data that show evidence for partial melt and magma intrusions in the crust and upper mantle beneath the MER and adjacent Ethiopian plateau (e.g., Bastow et al., 2005; Keir et al., 2005; Kendall et al., 2005; Rooney et al., 2005).

The high attenuation observed in Ethiopia is significantly different from the East African rift system in Tanzania where the crust and upper mantle have had little to no modification by rifting processes (Langston et al., 2002). In Tanzania, the combination of crystalline Archaean and Protorozoic crust, in conjunction with low geothermal gradients typical of Archaean craton give rise to very efficient wave propagation in the lithosphere (Langston et al., 1998; Weeraratne et al., 2003).

The new magnitude scale for Ethiopia is used to investigate seismicity of the MER for 2001-2003. Because of high attenuation in the MER, earthquakes located outside the network but recorded on EAGLE stations are $M_{\mathrm{L}}>\sim 3$ (Figs. 1 and 2). Therefore, we calculated magnitude statistics of the 1957 earthquakes located within the network of seismic stations. This ensures we sample an earthquake catalog that is not biased toward large earthquakes located outside the network and also ensures our magnitude statistics sample only earthquakes in the MER. Most earthquakes are of $M_{\mathrm{L}} 1-2$ and the largest earthquake is $M_{\mathrm{L}} 3.9$ (Fig. 8a). The powerlaw cumulative frequency-magnitude distribution shows that the seismicity catalog is complete above $M_{\mathrm{L}} 2.1\left(M_{\mathrm{c}} 2.1\right)$ 

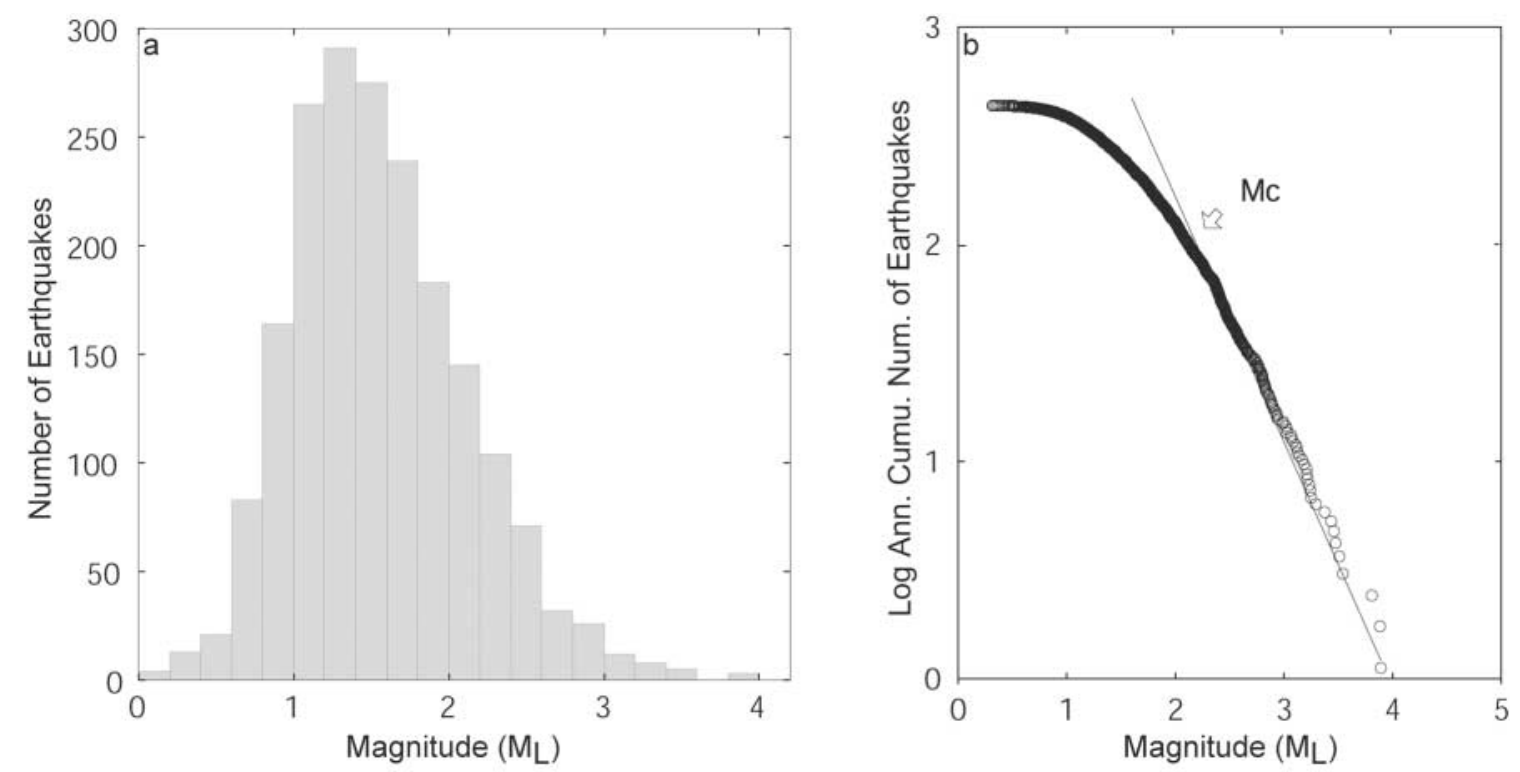

Figure 8. (a) Magnitude-frequency distribution of earthquakes recorded within the network of seismic stations. Most of the earthquakes are of magnitude $M_{\mathrm{L}} 1-2$ and the highest-magnitude earthquake is $M_{\mathrm{L}}$ 3.9. (b) Gutenburg-Richter distribution of earthquakes located within the network of seismic stations. $\mathrm{M} c$ is the cutoff magnitude of 2.1 and the slope shows $b=1.13$. The straight line intersects the $y$ axis at $y=4.5$.

(Fig. 8b) (Gutenberg and Richter, 1956). A $b$-value of 1.13 \pm 0.05 was estimated from earthquakes larger than the $M_{\mathrm{L}}$ 2.1 using the maximum-likelihood method (Aki, 1965) and an error estimate determined from the standard deviation of $b$ (Shi and Bolt, 1982). The cumulative annual seismicity rate is calculated from an annualized dataset and follows the relation $\log N=4.5-1.13 M_{\mathrm{L}}$. Hofstetter and Beyth (2003) obtained a $b$-value of $0.83 \pm 0.08$ from just 16 earthquakes on global and regional catalogs that were located across a larger area that encompasses both the MER and southern Ethiopian Rift as far south as $5^{\circ} \mathrm{N}$.

The relatively high $b$-value of 1.13 for seismicity in the MER during 2001-2003 is consistent with seismic energy being released mostly as swarms of lower magnitude $\left(M_{\mathrm{L}}\right.$ $<4)$ earthquakes (Keir et al., 2006). This pattern of seismicity is likely representative of longer-term deformation patterns as previous studies of seismicity in the MER also report lower-magnitude seismic swarms and a similar pattern is evident in data from global and regional catalogs that show relatively few larger magnitude $\left(m_{\mathrm{b}}>4.0\right)$ earthquakes in the MER (e.g., Gouin, 1979; Asfaw, 1982; Kebede and Kulhánek, 1994). The observed lack of large-magnitude earthquakes in the MER is consistent with geodetic data that show that the majority of strain across the MER is accommodated aseismically (Hofstetter and Beyth, 2003 Bendick et al., 2006). Studies of seismically active magmatic systems show that $M_{\mathrm{c}}$ and $b$-value can vary in space and time (e.g., Wiemer et al., 1998; Murru et al., 1999). The $b$-value obtained in our study is based on only 16 months of data from a $250 \mathrm{~km}$ $\times 350 \mathrm{~km}$ area and may thus be biased by short-term spatial and temporal variations in the pattern of seismic activity. A detailed appraisal of the recurrence interval of largemagnitude earthquakes can only be achieved with longerterm seismic monitoring in Ethiopia.

An estimated $b$-value of 1.13 for the MER is similar to $b$-values of 1.05-1.3 calculated for the southern Red Sea and Gulf of Aden seafloor spreading centers (Ayele and Kulhánek, 1997; Hofstetter and Beyth, 2003). Lower $b$-values of between 0.7 and 0.9 are observed in the East African rift system in southern Ethiopia, Kenya, and Tanzania where moment release as large-magnitude earthquakes located on rift-bounding border faults accommodates the majority of extension (e.g., Tongue et al., 1992; Langston et al., 1998).

Despite the lack of large earthquakes recorded over the past $\sim 50$ years in the MER, the recent dike-injection episode and associated swarm of earthquakes, surface fissuring, and volcanic eruption in Afar highlights the potential seismic hazard of rift zones in Ethiopia. Seismicity within the magmatic segments of the MER is likely controlled by episodic injection of dikes (Keir et al., 2006). Although a major rifting event has not yet been directly observed in the MER, structural data suggest that episodes of surface fissuring and volcanic eruptions have occurred in MER magmatic segments during the last $\sim 10,000$ years (e.g., Asfaw, 1982, 1998; Williams et al., 2004). Despite the current period of quiescence, hazards associated with seismicity and volcanic eruptions pose a serious risk to life and economy in the MER.

\section{Conclusions}

A local magnitude scale for Ethiopia has been developed from 30,908 amplitude measurements on simulated 
Wood-Anderson seismograms from 2139 earthquakes recorded on 122 EAGLE broadband instruments. The new magnitude scale uses a distance normalization of $10 \mathrm{~mm}$ motion at $17 \mathrm{~km}$ distance for a $M_{\mathrm{L}} 3.0$ earthquake. The distance correction is given by;

$$
\begin{aligned}
-\log \left(A_{\mathrm{o}}\right)=1.196997 & \log (r / 17) \\
+ & 0.001066(r-17)+2.0,
\end{aligned}
$$

where $r$ is hypocentral distance in kilometers. The distance correction shows that ground-motion attenuation in Ethiopia is relatively high and is consistent with the presence of pervasive magma intrusion and partial melt beneath the MER.

The catalog of events used in this study is complete above $M_{\mathrm{L}} 2.1$. The annual cumulative seismicity rate in the MER is $\log N=4.5-1.13 M_{\mathrm{L}}$. The relatively high $b$-value is consistent with the observed pattern of low magnitude $M_{\mathrm{L}}<4$ swarms of earthquakes in the MER and lack of largemagnitude earthquakes reported on global and regional catalogs over the past $\sim 50$ years.

The recent swarm of $163 m_{\mathrm{b}}>4.0$ earthquakes and volcanic eruption and surface fissuring in the Dabbahu magmatic segment in Afar highlights the potential seismic and volcanic hazard in volcanic rift zones such as the MER. Our results are critical for current and future quantitative analysis of seismicity in Ethiopia, which is important for scientific, economic, and social development.

\section{Acknowledgments}

We thank SEIS-UK for the use of instruments and especially Alex Brisbourne for assistance in the field, with data management and analysis. Cindy Ebinger, Eve Daly, Dave Cornwell, and Ian Bastow are thanked for their significant contributions to this study. Laike Asfaw of the Geophysical Observatory Addis Ababa University and Bekele Abebe, Dereje Ayalew, Gezahegn Yirgu, and Tesfaye Kidane are thanked for support throughout the project. Research was supported by NERC Grant NER/A/S/2000/01004 and NERC Studentship NER/S/A/2002/10547.

\section{References}

Alsaker, A., L. B. Kvamme, R. A. Hansen, and A. Dahle (1991). The $\mathrm{M}_{\mathrm{L}}$ scale in Norway, Bull. Seism. Soc. Am. 81, 379-398.

Aki, K. (1965). Maximum likelihood estimate of $b$ in the formula $\log N=$ $a-b \mathrm{M}$ and its confidence limits, Bull. Earthquake Res. Inst. 43, 237239.

Anderson, J. A., and H. O. Wood (1925). Description and theory of the torsion seismometer, Bull. Seism. Soc. Am. 15, 1-72.

Anderson, J. G., and Y. Lei (1994). Nonparametric description of peak acceleration as a function of magnitude, distance and site in Guerrero, Mexico, Bull. Seism. Soc. Am. 84, 1003-1017.

Asfaw, L. M. (1982). Development of earthquake induced fissures, Nature 286, 551-553.

Asfaw, L. M. (1988). Catalogue of Ethiopian earthquakes, earthquake parameters, strain release and seismic risk, in Proceedings of the SAREC-ESTC Conference on Research Development and Current Research Activities in Ethiopia, G. Woldeyes (Editor).

Asfaw, L. M. (1998). Environmental hazard from fissures in the Main Ethiopian rift, J. Afr. Earth Sci. 27, no. 3/4, 481-490.

Ayele, A., and O. Kulhánek (1997). Spatial and temporal variation of the seismicity in the Horn of Africa from 1960-1993, Geophys. J. Int 130, 805-810.

Bakun, W. H., and W. B. Joyner (1984). The $\mathrm{M}_{\mathrm{L}}$ scale in central California, Bull. Seism. Soc. Am. 74, 1827-1843.

Bastow, I. D., G. W. Stuart, J-M. Kendall, and C. J. Ebinger (2005). Upper mantle seismic structure in a region of incipient continental breakup: northern Ethiopian rift, Geophys. J. Int. 162, 479-492.

Baumbach, M., D. Bindi, H. Grosser, C. Milkereit, S. Parolai, R. Wang, S. Karakisa, S. Zünbül, and J. Zschau (2003). Calibration of an $\mathrm{M}_{\mathrm{L}}$ scale in northwestern Turkey from 1999 Izmit aftershocks, Bull. Seism. Soc. Am. 93, 2289-2295.

Bendick, R., S. McClusky, R. Bilham, L. Asfaw, and S. Klemperer (2006). Distributed Nubia-Somalia relative motion and dike intrusion in the Main Ethiopian rift, Geophys. J. Int. 165, 303-310.

Bilham, R., R. Bendick, K. Larson, P. Mohr, J. Braun, S. Tesfaye, and L. Asfaw (1999). Secular and tidal strain across the Main Ethiopian rift, Geophys. Res. Lett. 26, 2789-2792.

Bormann, P. (2002). Magnitude of seismic events, in IASPEI New Manual of Seismological Observatory Practice. Vol. 1, P. Bormann (Editor), GeoForschungsZentrum, Potsdam, 16-50.

Bragato, P. L., and A. Tento (2005). Local magnitude in northeastern Italy, Bull. Seism. Soc. Am. 95, 579-591.

Ebinger, C., and M. Casey (2001). Continental breakup in magmatic provinces, an Ethiopian example, Geology 29, 527-530.

Gouin, P. (1979). Earthquake History of Ethiopia and the Horn of Africa, International Development Research Centre (IDRC), Ottawa, Ontario, $258 \mathrm{pp}$.

Gutenberg, B., and C. F. Richter (1956). Earthquake magnitude, intensity, energy, and acceleration, Bull. Seism. Soc. Am. 46, 105-145.

Hofstetter, R., and M. Beyth (2003). The Afar Depression: interpretation of the 1960-2000 earthquakes, Geophys. J. Int. 155, 715-732.

Hutton, L. K., and D. M. Boore (1987). The $\mathrm{M}_{\mathrm{L}}$ scale in southern California, Bull. Seism. Soc. Am. 77, 2074-2094.

Kanamori, H., and P. C. Jennings (1978). Determination of local magnitude, $\mathrm{M}_{\mathrm{L}}$, from strong motion accelerograms, Bull. Seism. Soc. Am. 68, 471-485.

Kebede, F., and O. Kulhánek (1991). Recent seismicity of the East African rift system and its implications, Phys. Earth Planet. Interiors 68, 259-273.

Kebede, F., and O. Kulhánek (1994). Spatial and temporal variations in $b$ values along the East African rift system and the southern Red Sea, Phys. Earth Planet. Interiors 83, 249-264.

Kebede, F., and T. van Eck (1997). Probabilistic seismic hazard assessment for the Horn of Africa based on seismotectonic regionalization, Tectonophysics 270, 221-237.

Keir, D., C. J. Ebinger, G. W. Stuart, E. Daly, and A. Ayele (2006). Strain accommodation by magmatism and faulting as rifting proceeds to breakup: seismicity of the northern Ethiopian rift, J. Geophys. Res. 111, no. B5, B05314, doi 1029/2005JB003748.

Keir, D., J-M. Kendall, C. J. Ebinger, and G. W. Stuart (2005). Variations in late syn-rift melt alignment inferred from shear-wave splitting in crustal earthquakes beneath the Ethiopian rift, Geophys. Res. Lett. 32, L23308, doi 10.1029/2005GL024150.

Kendall, J-M., G. W. Stuart, C. J. Ebinger, I. D. Bastow, and D. Keir (2005). Magma assisted rifting in Ethiopia, Nature 433, 146-148.

Kendall, J-M., S. Pilidou, D. Keir, I. D. Bastow, A. Ayele, and G. W. Stuart (2006). Mantle upwellings, melt migration and the rifting of Africa: insights from seismic anisotropy, in The Afar Volcanic Province within the East African Rift System, G. Yirgu, C. J. Ebinger, and P. K. H. Maguire (Editors), Geol. Soc. Spec. Publ. 259, 55-72.

Keranen, K., S. L. Klemperer, R. Gloaguen, and Eagle Working Group (2004). Three-dimensional seismic imaging of a protoridge axis in the Main Ethiopian rift, Geology 32, 949-952.

Kim, W-Y. (1998). The $\mathrm{M}_{\mathrm{L}}$ scale in eastern North America, Bull. Seism. Soc. Am. 88, 935-951.

Kim, S. K., and M. A. Park (2005). The local magnitude scale in the Korean Peninsula, Pure Appl. Geophys. 162, 875-889. 
Klein, F. W. (2002). User's Guide to Hypoinverse-2000, a Fortran program to solve for earthquake locations and magnitudes, U.S. Geol. Surv. Open File Rept. 02-171, 1-123.

Langston, C. A., A. A. Nyblade, and T. J. Owens (2002). Regional wave propogation in Tanzania, East Africa, J. Geophys. Res. 107, doi 10.1029/2001JB000167.

Langston, C. A., R. Brazier, A. A. Nyblade, and T. J. Owens (1998). Local magnitude scale and seismicity rate for Tanzania, East Africa, Bull. Seism. Soc. Am. 88, 712-721.

Maguire, P. K. H., G. R. Keller, S. L. Klemperer, G. D. Mackenzie, K. Keranen, S. Harder, B. O’Reilly, H. Thybo, L. Asfaw, M. A. Khan, and M. Amha (2006). Crustal structure of the northern main Ethiopian Rift from the EAGLE controlled source survey; a snapshot of incipient lithospheric break-up, in The Afar Volcanic Province within the East African Rift System, G. Yirgu, C. J. Ebinger, and P. K. H. Maguire (Editors), Geol. Soc. Spec. Publ. 259, 269-292.

Mammo, T. (2005). Site-specific ground motion simulation and seismic response analysis at the proposed bridge sites within the city of Addis Ababa, Ethiopia, Eng. Geol. 79, 127-150.

Murru, M., C. Montouri, M. Wyss, and E. Privitera (1999). The locations of magma chambers at Mt. Etna, Italy, mapped by $b$-values, Geophys. Res. Lett. 26, 2553-2556.

Ortega, R., and L. Quintanar (2005). A study of local magnitude scale in the basin of Mexico: mutually consistent estimates of $\log A_{\mathrm{o}}$ and ground motion scaling, Bull. Seism. Soc. Am. 95, 605-613.

Pujol, J. (2003). Determination of a local magnitude scale: a generalized inverse solution, Bull. Seism. Soc. Am. 93, 2758-2761.

Richter, C. F. (1935). An instrumental earthquake magnitude scale, Bull. Seism. Soc. Am. 25, 1-31.

Richter, C. F. (1958). Elementary Seismology, W. H. Freeman and Co., San Francisco, 578 pp.

Rooney, T. O., T. Furman, G. Yirgu, and D. Ayalew (2005). Structure of the Ethiopian lithosphere: xenolith evidence in the Main Ethiopian rift, Geochem. Cosmochim. Acta 69, 3889-3910.

Savage, M. K., and J. G. Anderson (1995). A local-magnitude scale for the western Great Basin-Eastern Sierra Nevada from synthetic WoodAnderson seismograms, Bull. Seism. Soc. Am. 85, 1236-1243.

Schlotterbeck, B. A., and G. A. Abers (2001). Three-dimensional attenuation variations in southern California, J. Geophys. Res. 106, 30,71930,735 .

Shi, Y., and B. A. Bolt (1982). The standard error of the magnitudefrequency $b$-value, Bull. Seism. Soc. Am. 72, 1677-1687.
Tongue, J. A., P. K. H. Maguire, and P. Burton (1992). Seismicity distribution from temporary earthquake recording networks in Kenya, Tectonophysics 204, 71-79.

Weeraratne, D. S., D. W. Forsyth, K. M. Fischer, and A. A. Nyblade (2003). Evidence for an upper mantle plume beneath the Tanzanian craton from Rayleigh wave tomography, J. Geophys. Res. 108, no. B9, 2427 , doi 10.1029/2002JB002273.

Wiemer, S., S. R. McNutt, and M. Wyss (1998). Temporal and threedimensional spatial analyses of the frequency-magnitude distribution near Long Valley Caldera, California, Geophys. J. Int. 134, 409-421.

Whaler, K. A., and S. Hautot (2006). The electrical resistivity structure of the crust beneath the northern Ethiopian rift, in The Afar Volcanic Province within the East African Rift System, G. Yirgu, C. J. Ebinger, and P. K. H. Maguire (Editors), Geol. Soc. Spec. Publ. 259, 293-306.

Williams, F. M., M. A. J. Williams, and F. Aumento (2004). Tensional fissures and crustal extension rates in the northern part of the Main Ethiopian rift, J. Afr. Earth Sci. 38, 183-197.

Wright, T. J., C. Ebinger, J. Biggs, A. Ayele, G. Yirgu, D. Keir, and A. Stork (2006). Magma-maintained rift segmentation at continental rupture in the 2005 Afar dyking episode, Nature 442, doi:10.1038/nature04978.

Yirgu, G., A. Ayalew, A. Asrat, A. Ayele, and A. Philpotts (2005). Bulletin of the Global Volcanism Network, September 2005, Dabbahu, Ethiopia, www.volcano.si.edu/reports/bulletin (last accessed September 2006).

Department of Geology

Royal Holloway University of London

Egham, Surrey, TW20 0EX, United Kingdom

d.keir@gl.rhul.ac.uk

(D.K.)

School of Earth and Environment

University of Leeds

Leeds, LS2 9 JT, United Kingdom

graham@earth.leeds.ac.uk

(G.W.S., A.J.)

Geophysical Observatory

Addis Ababa University

Addis Ababa, P.O.B. 1176, Ethiopia

atalay@geobs.aau.edu.et

(A.A.)

Manuscript received 9 March 2006 